\title{
La guerra y la paz, o un nuevo refuerzo francés a la derecha mexicana
}

\section{Moisés González Navarro}

\begin{abstract}
L'ouvrage de P. Smith est en effet digne d'éloge pour le travail de compilation considérable qu' il suppose, pour le traitement sophistiqué auquel il soumet son corpus bibliographique, pour son souci constant de marquer les limites et l'étendue de sa demonstration. François-Xavier Guerra, Le Mexique, II, p. 495.
\end{abstract}

El belicoso autor que firma el comentario arriba citado honra su apellido: ha declarado la guerra a los malandrines (historias generales e historias oficiales), y se ha constituido en defensor de su Dulcinea: las historias regionales y las historias defensoras del Antiguo Régimen. Sin duda es un libro importante por su ambicioso empeño innovador. Consta de dos volúmenes con un total de 988 páginas. El primer tomo se inicia con un prefacio de François Chevalier (honra su apellido), autor del célebre libro sobre La formación de los grandes latifundios en México y algunos sugerentes artículos sobre los siglos XIX y XX.

En el primer tomo estudia la ficción y la realidad de un sistema político y los trastornos de la paz, en el segundo las raíces y razones de un hundimiento. También incluye las conclusiones, los anexos y la bibliografía. Aquéllos comprenden el sistema informático, el corpus bibliográfico general y los cargos políticos porfirianos, la geografía política, el Porfíriato, la población rural: la trampa de los términos y las cifras, fenómenos sociales y políticos, a propósito de un libro (Los laberintos del poder de Peter $\mathrm{H}$. Smith), fuentes y bibliografía. En fin, indices, 51 mapas, 39 cuadros y uno temático.

El prefacio exalta con entusiasmo tropical las excelencias de la obra, acaso este desbordamiento se explique por los muchos años que el prologuista vivió en México. En efecto, según Chevalier, del modelo central de la Revolución francesa deriva el modelo mexicano periférico. Este puede a su vez aclarar el central y, además, abrir posibilidades de comparación, en particular con el mundo latino. El modelo central es tanto más operativo cuanto más elaboradas y completas sean las bases "informatizadas" que lo apuntalen: un corpus bibliográfico o fichero de unas ocho mil personas o actores sociales y ciento cincuenta mil datos. Ayudó a elaborar el banco de datos un numeroso equipo de estudiantes de la Sorbona. En el centro de la obra se encuentra un modelo teórico de relaciones difíciles entre dos mundos totalmente diferentes y extraños el uno para el otro: un Estado moderno salido de la Ilustración y dirigido por una pequeña minoría de ciudadanos conscientes, frente a una enorme sociedad tradicional u holliste, todavía del antiguo régimen, colonial, añade Chevalier. Con este modelo se podría reinterpretar toda la historia de México desde la Independencia, principalmente los orígenes y la naturaleza profunda de la Revolución mexicana. 
La Constitución de 1857 pertenece a un ideal constantemente invocado pero completamente inaplicable en una sociedad tradicional que muestra evidentes retrasos frente a Europa. En esa sociedad tradicional no podían tener ningún sentido el sufragio universal ni la separación de los poderes en un pueblo formado casi exclusivamente por actores colectivos y grupos sociales muy contraignants. El Estado moderno sólo tenía frente a sí comunidades indias o campesinas aún coherentes, haciendas, enclaves señoriales, clanes familiares, redes de lazos personales y clientelas; en fin, una multitud de cuerpos, pequeños y grandes, firmemente homogeneizados, y un gigante, la Iglesia, como orden siempre omnipresente, y vista como clave de bóveda de todo el antiguo edificio sociopolítico, por tanto, el enemigo número uno de esa constitución. Esta útil reflexión debe completarse recordando que se trata de un proceso en el que, al lado de un mundo tradicional que se transforma, aparece una naciente clase obrera y una clase media ilustrada (que estudió bien Luis Chávez Orozco) y una incipiente verdadera burguesía.

Según Chevalier, después de diversos avatares, la Revolución regresa a sus fuentes. Conscientemente o no, toma ciertos rasgos de la Revolución francesa o se percibe como ella: convención de Aguascalientes, asimilación de Porfirio Díaz al antiguo régimen, levantamiento del "pueblo" contra la "tirania", en suma, el advenimiento de los tiempos nuevos. Contra la tendencia del siglo pasado que se preguntaba cómo extirpar al cacique, Guerra ve en éste un lazo necesario, estructural, entre dos mundos heterogéneos. Muy importante le parece la "rectificación" sobre la propiedad comunal de los pueblos. Sobre este tema volveremos al final del comentario.

El prologuista se pregunta si se puede calificar de "eurocentrista" una obra que no estudia sino marginalmente los rasgos específicos americanos. Por supuesto que no, es sólo "franciscocentrista". En opinión del prologuista, el autor sigue un método "riguroso e irreprochable", sitúa en una realidad muy compleja un gran problema sociopolítico, uno de los ejes de la historia de México desde la Independencia: la contradicción entre el tipo de dominación de la sociedad y el sistema moderno de legitimación democrático, utilizado por una minoria ilustrada. Las observaciones hechas o por hacer a la obra, en el mejor de los casos, no pueden sino matizar este modelo innovador, cuya sencillez lo hace más operativo para el análisis de casos análogos. Chevalier concluye arrogante: esta obra de Guerra es "excepcionalmente rica y fecunda, por su método riguroso, por las bases que le dan la informática, más aún, por su nuevo y original enfoque, que da otra dimensión a la historia de México". Este notable modelo rebasa no sólo el caso mexicano, alcanza lo universal: C'est le propre d'un grand livre.'

El autor preparó el libro de 1971 a 1981. Su propósitó inicial era estudiar la Revolución mexicana, sobre la cual, informa a sus lectores, se han escrito millares de libros. El rescata, entre los que tienen méritos científicos, siete. Además, en lugar de estudiar los vicios latinoamericanos (caudillismo, caciquismo, nepotismo, mi-

Francois-Xavier Guerra, Le Mexique. De l'Ancien Régime à la Révolution, París, L'Harmattan, Publications de la Sorbonne, 1985, t. 1, p. 8-15. 
litarismo, etc.) invierte la perspectiva: "reconstruir le vécu des acteurs".

Asimismo denuncia la distancia que existe entre una historia nacional (propicia a todas las generalizaciones, aun las menos fundadas) y una historia regional cargada de la savia de lo concreto, de lo diverso, próxima a la realidad social y política vivida. Su sistema informático consta actualmente de 7838 individuos y 30450 módulos diferentes, que representan aproximadamente 150000 datos. El cuerpo incluye: 1) personas que ocuparon cargos políticos, 2) militares, 3) enemigos de ese régimen político, 4) levantamientos revolucionarios, 5) elites locales. ${ }^{2}$

Por otra parte, explica la guerra de Independencia por las crisis mineras y de subsistencias y, sobre todo, por la lucha de la sociedad contra el Estado moderno, es decir, la reacción contra la racionalización administrativa, el regalismo, la primera desamortización y la invasión de los funcionarios peninsulares. En su primera fase es una revuelta del tipo antiguo: "¡Viva Fernando VII! ¡Muera el mal gobierno!"' Esta explicación es válida pero incompleta. Hidalgo, al abolir el estanco de la pólvora y de los naipes y decretar la libertad del cultivo del vino y del tabaco, benefició a los criollos. La desaparición de las cajas de comunidad debilitó a los indios; los fortaleció la restitución de sus tierras, en menor grado la abolición del tributo y de la esclavitud. ${ }^{4}$ Es natural que apruebe la justicia de muchos juicios "desmitificadores" de Lucas Alamán (revalorar el pasado hispánico y preconizar el abandono de las ideas liberales), y lamente que los conservadores siempre hayan sido "liberales tibios".

Le parece que las leyes de Maximiliano, favorables a las comunidades indígenas, dejaron "huellas manifiestas". Sólo ofrece como prueba de esa afirmación la elección de los miembros de las municipalidades.

El Porfiriato es central en este libro. No lo considera como el Antiguo Régimen, sino como un compromiso o equilibrio entre dos mundos heterogéneos. ${ }^{7}$ Del igualitarismo liberal sólo ve el lado catastrófico, cosa ciertísima: las comunidades perdieron la libertad de tener derechos propios. ${ }^{8}$ En cambio, no advierte que con él la sociedad estamental se transformó en clasista y se incrementó la dignificación del mestizaje y la conciencia nacional.

Con un argumento de autoridad exalta el porfiriato: para José María Vigil los mexicanos tenían como verdad indiscutible el bienestar social que reinaba de un extremo a otro de la República: garantias para la vida y la propiedad. La paz no se mantenía por medios coactivos. ${ }^{9}$

Según el autor, la tregua "implícita" entre los pueblos y Porfirio

${ }^{2}$ Ibid., t. I, p. 17-18, 53, 84; t. II, p. 349-351.

3 Ibid., t. I, p. 173.

4 Moisés González Navarro, "La Independencia, El Yorkinato y la Libertad", en Extremos de México, México, El Colegio de México, 1971, p. 153.

${ }^{5}$ Guerra, op. cit., t. I, p. 189.

${ }^{6}$ Ibid., t. 1, p. 248-249.

7 Ibid., t. I, p. 22.

${ }^{8}$ Ibid., t. I, p. 237.

9 Ibid., t. I, p. 197. 
Díaz aseguró hasta 1890 las tierras de muchos pueblos. Prueba afirmación tan temeraria con el recuerdo del Pedro Martinez de Oscar Lewis, quien habla del Porfiriato como de una época de justicia. Temeroso de la ligereza de este argumento, reconoce el descontento popular rural en excepciones locales, como en la Huasteca, excéntrica y poco integrada al resto del país. Considera "probable", sin más base que su palabra, que hubo frente a los pueblos una política de conciliación semejante a la de la Iglesia. Algunos pueblos perdieron sus tierras, pero esto ocurrió antes de Porfirio Díaz; de cualquier modo en el antiguo régimen, añadimos nosotros. Aquél hizo sentir a los pueblos el recuerdo de la autoridad real; no siempre les dio la razón, pero siempre los escuchó. También cree probar su opinión con el argumento de que Eufemio Zapata presidió el club porfirista de Anenecuilco hasta 1892, fidelidad sólo comprensible porque, en cambio, recibía servicios, y estos no podian (subrayado de MGN) ser otros que la protección del pueblo.

Admite que los pequeños propietarios, salvo los pueblos de indios, fueron despojados de sus tierras y de sus aguas. Cree justificar esta tesis con la extraordinaria desproporción entre el $0.5 \%$ de restituciones y el $99.5 \%$ de dotaciones a muchos que jamás las habian poseido. Su fuente es digna de ese disparate jurídico e histórico: Jorge Vera Estañol. ${ }^{10}$ Es disparate porque ignora que cuando los ejidatarios advirtieron la dificultad de encontrar las pruebas de sus derechos a la restitución, optaron por solicitar directamente la dotación, sin que esto signifique que no hubieran sido los dueños de las tierras solicitadas.

El autor pontifica, una vez más, cuando asegura que el Porfiriato "siempre" proscribió las armas para resolver los conflictos, y basa su opinión en que los efectivos del ejército eran "ridículos": 18000 soldados (al parecer se refiere a 1909) insuficientes para cubrir las plazas de las ciudades, pero olvida la policía rural. La verdadera fuerza de ese régimen, añade, era el consensus de los actores sociales. La coacción sólo se destinó a los marginales o a las dificultades locales. Las unidades colectivas englobaban aún a la mayoria de la población, la cohesión interior y las reglas internas fueron la más fuerte garantía de la paz."

Sin embargo, aún antes de 1890 puede recordarse un catálogo mínimo de las luchas de las haciendas y los pueblos. José Ives Limantour, propietario de la hacienda de la Tenería, Estado de México, se apoderó de las tierras de San Simonito Tlacomulco. Inútilmente, este pueblo, desde octubre de 1869 , por medio de dos diputados, intentó el apeo y deslinde de esas tierras. Los vecinos de San Nicolás Peralta y los de la hacienda de Santa Catarina, también en el Estado de México, pidieron a la legislatura local autorización para constituirse en pueblos; mientras el anterior propietario (Gregorio Mier y Terán) estaba de acuerdo con esa petición, el nuevo (Isidoro de la Torre) echó a los peticionarios, con lujo de fuerza, de la hacienda. Otro de los casos más sonados fue la invasión del rancho de San Vicente por la hacienda de Bocas, San Luis Potosí. Muy antiguos eran los abusos de esa ha-

${ }^{10}$ Ibid., t. I, p. 50, 209-212.

"Ibid., t. I, p. 198. 
cienda en perjuicio de los arrendatarios; a mediados de 1878 la hacienda expulsó por la fuerza a los habitantes del rancho.

Numerosos pueblos del Estado de México litigaban con las haciendas colindantes, que habían acabado por apoderarse de sus tierras y arrendárselas a sus antiguos propietarios. Una disputa de 25 años entre el pueblo de San Miguelito y la hacienda de la Gavia tuvo un desenlace trágico a principios de 1892. Entretanto, amigos de Teodoro Dehesa, gobernador de Veracruz, despojaban a los indios de Chiconciago, Jalapa, y las haciendas duranguenses hacian lo mismo. Por entonces 65 pueblos poblanos luchaban entre sí o con los hacendados vecinos. Las autoridades de ese estado reconocieron que, salvo la región norte, los hacendados apenas habían dejado el terreno estrictamente indispensable para el fundo de las poblaciones. Estos litigios fueron aún más graves en Hidalgo, donde los indios fueron acusados de comunistas. Representantes de los pueblos indígenas de los estados de Hidalgo, México, Morelos, Distrito Federal, Michoacán y Veracruz se quejaron, el primero de mayo de 1878 , ante el Congreso de la Unión por la usurpación de sus tierras y los miserables jornales que percibían; la Cámara respondió, en octubre de ese año, declarándose incompetente para resolver el asunto. En marzo del año siguiente se celebró una primera junta del Congreso de los pueblos indígenas de la República, para estudiar la defensa de sus tierras.

El pueblo de San Bernabé, municipalidad de San Angel, en 1875 saqueó la hacienda de la Cañada. El coronel Alberto Santa Fe y el abogado Manuel Cerdán planearon ese mismo año que toda familia mexicana con un capital inferior a 3000 pesos obtendría del gobierno nacional, pagaderas en diez años, una fanega de sembradura de maíz, una yunta de bueyes y un arado por cada hijo varón; se otorgaría agua, bosques y pastos a los pueblos. Este proyecto fue aprobado por el pueblo de San Mateo Tepetitlán porque sus 1018 habitantes sólo disponían de una caballeria de tierra; lo mismo hicieron 2214 obreros de Tlalnepantla. Alberto Santa Fe sublevó algunos indios de Texmelucan, Puebla; tras ser vencido, fue absuelto. Un año después algunos pueblos de Guanajuato y de Querétaro condenaron la esclavitud de las haciendas, la inmensidad de las tierras incultas y los despojos a los indígenas, a su triunfo se las devolverían. Sin embargo nada cambió, fuera de anunciar la Revolución.

Mucho más graves fueron las rebeliones de Alica, antigua guarida de Manuel Lozada; el plan de Tepic de 1879 ofreció revisar los títulos de propiedad para devolver las tierras a los indios. En 1884 fracasó un nuevo levantamiento por estos rumbos lozadeños. También fracasaron sendos lẹvantamientos agrarios en Tepic y en Zacatecas; años después Tamazunchale, y en general, todo el estado de San Luis Potosí fue foco de constantes conflictos agrarios en $1879,1881,1882$ y 1883 . En este último año, 60 arrendatarios de una hacienda de Ciudad del Maíz, también San Luis Potosí, se rehusaron a pagar al propietario alegando la ley agraria proclamada por el cura Zavala. Poco después 400 individuos saquearon varias haciendas. Los indios de Tancanhuitz y Tamanzunchale, capitaneados por el cura Zavala, se apoderaron de tierras de estas poblaciones, pero pronto fueron vencidos. Sólo 4 días duró una rebelión indígena en Veracruz en 1881; mayor duración tuvo otra 
dos años después. En Acayucan se mezclaron en la lucha la tierra y la religión, y la xenofobia en Papantla. ${ }^{12}$ Importa recordar estos conflictos porque muchos de ellos distan de ser excéntricos. Sin embargo, como me baso en El Porfiriato. La Vida Social, una historia general, no merezco crédito, pero tal vez sí $\mathrm{L}$. Reina, al menos, como lo veremos después, cuando el autor cree que apoya al antiguo régimen.

El autor tiene una concepción histórica voluntarista, sobre todo cuando se trata de sus héroes, Porfirio Díaz y Maximiliano. En efecto, atribuye al olfato de Diaz que, por ejemplo, en Morelos sólo un pueblo hubiera desaparecido antes de 1910, si bien desde 1900 se había desarrollado un gran proceso de expoliación de los pueblos en ese estado. Díaz perđió el olfato para mantener el equilibrio social y político en Morelos, olvidó cada vez más "los mecanismos y el tipo de hombres que le habian permitido mantenerse en el poder". Asimismo, ve en la represión contra yaquis y mayas en 1901 no una ofensiva contra revoltés, sino un enfrentamiento entre el México moderno y tribus indígenas exteriores. ${ }^{13}$ En efecto, mientras que los mayas rebeldes después de la guerra de castas fueron arrinconados en lo que hoy es Quintana Roo, los pacíficos permanecieron en el resto de la península crecientemente atados a la hacienda. Pero en Sonora la situación fue diferente. La frontera no fue tan tajante, pues los rebeldes, que no quedaron totalmente aislados, algunas veces proporcionaron fuerza de trabajo a ranchos y minerales de Ures, Hermosillo y Guaymas. ${ }^{14}$

Rechaza que algunos consideren inmóvil, hasta bipolar (hacendados-peones), el México rural. ${ }^{15}$ Atribuye a George McCutchen Mc Bride The Land System of Mexico, Frank Tannembaum, La Revolución Agraria Mexicana, y a mis Estadísticas Sociales del Porfiriato este agravio académico. A los autores norteamericanos les hubiera correspondido defenderse, pero como parece que están muertos, no podrán hacerlo (caso que les hubiera interesado, yo lo haré al final de este comentario).

Dentro de su prurito apologético de la hacienda, asegura que no sería sorprendente que "estudios precisos" del nivel de instrucción de ésta demuestren que fue superior al de muchas poblaciones independientes pero dispersas. Puesto en la tesitura de especular, nada parece detenerlo cuando favorece su causa. Como los pueblos estaban en plena transformación al fin del siglo XVIII se pregunta ¿cómo habría proseguido ese cambio? No sabemos nada en definitiva, se responde pero puede ser (subrayado de MGN) que se hubieran multiplicado los pueblos blancos y mestizos en las tierras casi vacías del norte y se hubieran fragmentado las haciendas no rentables, dando lugar a nuev̀os pueblos y pequeñas propiedades, en fin, a la modernización progresiva de los pueblos indios. 16

${ }^{12}$ González Navarro, El Porfiriato. La Vida Social, México, Editorial Hermes, 1957, p. 240-244. Leticia Reina, Las Rebeliones campesinas en México (18191906), México, Siglo XXI, 1980, p. 136, 200, 419-420.

${ }_{13}^{13}$ Guerra, op. cit., t. I, p. 198; t. II, p. 101, 105, 241, 243.

14 González Navarro, El Porfiriato..., op. cit., p. 247-249, 252.

15 Guerra, op. cit., t. I, p. 270.

16 Ibid., t. I, p. 243, 375. 
Defiende la unión de la hacienda y de la Iglesia; según él, la sociedad mexicana era "profundamente católica". "Si el autor hubiera trabajado más fuentes primarias, acaso se habría tropezado con la Historia del Congreso Constituyente de Francisco Zarco, donde habría podido leer el discurso en que José Maria Mata niega la unidad religiosa de México, porque existian los indios idólatras, los verdaderos católicos y los indiferentes. ${ }^{18}$

Recuerda que una misa de navidad en la Gavia fue "verdaderamente artística", aunque acepta que esa descripción puede ser demasiado benévola y estar rodeada con el aura de la infancia; sin embargo, la juzga colorida y vívida. Ve la hacienda como una colectividad jerarquizada, donde cada uno tiene su rango; el amo es lujoso, pero tiene el deber de la munificencia (no precisa cómo cumplió con esa obligación). La supuesta profundidad del catolicismo no tiene esa generalidad, ya que él mismo, en otra ocasión, comenta la recristianización que emprendió Francisco Orozco y Jiménez en el obispado de San Cristóbal de las Casas. ${ }^{19}$

Con gran entusiasmo defiende la política obrerista del Porfiriato. Que lo guia la pasión, no el estudio, lo prueba su afirmación de que quelques grèves commencent à montrer l'apparition d'une question ouvrière en 1904. Pero es de sobra conocido que hubo huelgas en la Colonia misma, por ejemplo, la muy célebre del Real del Monte de 1766.

El número de las huelgas crece con el desarrollo económico del siglo XIX. El presidente recomendó al gobernador de Sonora en 1906 adoptar una actitud vigilante y neutral en la huelga de Cananea, porque los obreros tenían el derecho de no trabajar, siempre que no perturbaran el orden; criterio, por otra parte, acorde con el código penal de 1871. Aunque Díaz consideró exorbitantes las demandas de los ferrocarrileros en 1908, poco después les ofreció intervenir para lograr una solución "justa y legítima". En la huelga textil de 1906-1907, que culminó en la tragedia de Río Blanco de 1907, señala que el laudo presidencial rebasa las reivindicaciones de los obreros, salvo la exigencia de una libreta del trabajo que fué rechazada. Acepta la autoridad de Daniel Cosío Villegas, cuando la Historia Moderna de México coincide con sus intereses: Diaz no fue cómplice de los industriales, actuó por el deseo de lograr un control policiaco. En suma, Porfirio Díaz no desarrolló una política sistemáticamente represiva y antiobrera. Sin embargo, no hay que olvidar que al comentar la huelga de Cananea, escribió que el presidente intervino presionado por Creel, Félix Díaz y R. Corral. Creel, gobernador de Chihuahua, como se sabe, fue el enlace entre la oligarquía porfirista y los capitalistas extranjeros. ${ }^{20}$

Le parece extraño que coincidan los intereses del Estado moderno y los de las nuevas categorías sociales que pone a su servicio. En su opinión, esas elites son mucho más que "una burguesía

17 Ibid., t. I, p. 167.

18 Francisco Zarco, Historia del Congreso Constituyente, México, Imprenta de I. Cumplido, t. I, p. 785.

${ }_{19}$ Guerra, op. cit., t. I, p. 123, 417; t. II, p. 295.

20 Ibid., t. II, p. 50-51, 57-92. González Navarro, Anatomia del Poder en México (1848-1853), México, El Colegio de México, 1977, p. 198-205. Mark Wasserman, "Oligarquía e intereses extranjeros en Chihuahua durante el Porfiriato", en Historia Mexicana, vol. XXII enero-marzo 1973, núm. 3, p. 198-205. 
imaginaria", el verdadero fundamento social del régimen. ${ }^{21} \mathrm{La}$ denominación de burguesía la usó Justo Sierra y, de cualquier modo, no es imaginaria por el hecho de que no coincida con el modelo central. En efecto, al final del Porfiriato, existe una burguesia incipiente pero verdadera, compuesta no sólo por los científicos, prestanombres de los capitalistas extranjeros (la familia Madero sería un ejemplo sobresaliente, pero no el único). Caso semejante es su tesis de que la categoría de hacendado no responde a un clivage social, "como se ha repetido hasta la saciedad", es decir, no significa conservador ni liberal. ${ }^{22}$ Sin embargo, esto debe matizarse. Lucas Alamán pidió a Santa Anna, el 23 de marzo de 1853, que regresara a México; lo hizo en nombre de los conservadores, es decir, de los propietarios, del clero y de todos los que querían el bien de "su patria". Y tales propietarios son, en primer lugar, los hacendados. En efecto don Lucas, en esa misma carta, denunció que Melchor Ocampo tomó medidas alarmantes contra los dueños de terrenos. ${ }^{23}$ Es verdad que algunos importantes liberales fueron hacendados, entre ellos el propio Ocampo y Juan Alvarez, pero al grupo tradicionalista, mayoritario entonces, lo capitaneaba Alamán. También es cierto que con el desarrollo económico del norte algunos hacendados de esa región adquirieron un carácter "moderno".

Por otra parte, el autor explica que en el régimen político sobresale un solo elector: el presidente. La Cámara de Diputados era como un museo de historia natural en el que se encontraba un espécimen de cada especie, según él, de "los más honorables". Pese a la ausencia de una representación democrática real, los diputados en cierta manera realmente representaban al pais, es decir, a las familias o grupos que ejercian el poder con el presidente y los gobernadores. Esos grupos formaban parte de los clanes familiares con influencia política o de dinero; también destacan las elites de la inteligencia. Al final del Porfiriato la Cámara de Diputados tenía un perfume del Antiguo Régimen o de precorporativismo. Aunque sólo representaba pero no ejercía el poder, su papel no era despreciable. El poder real circulaba a través de la jerarquía del ejecutivo: del presidente a los gobernadores, que pertenecian, en su mayor parte, a un medio muy diferente. De cualquier modo, insiste en que el Porfiriato no se sostuvo sólo por la fuerza. ${ }^{24}$ Esto es cierto, pero no explica que una de las más importantes razones de la pacificación del país fue que la expansión económica proporcionó trabajo, algunas veces mejor remunerado, pero que también agudizó las seculares contradicciones sociales. ${ }^{25}$ Pese a que las inversiones extranjeras fueron realmente el motor de la expansión económica no estudió este tema lo suficiente.

En cambio, se ocupa con amplitud de la educación, con el deseo de probar que fue mejor atendida por el Antiguo Régimen que durante el Porfiriato. Lo hace con cifras "inverosimiles pero cier-

21 Guerra, op. clt., t. I, p. 284.

22 lbid., t. I, p. 62.

${ }^{23}$ González Navarro, Anatomia..., op. cit., p. 363.

${ }^{24}$ Guerra, op. cit., t. I, p. 100-103, 165.

${ }^{25}$ González Navarro, "La era moderna", en Historia Documental de México, México, Universidad Nacional Autónoma de México, 1964, t. II, p. 343. 
tas": en 1820 los niños escolarizados gratuitamente entre los 6 y los 12 años sumaban entre el 48 y el $62 \%$. Aunque reserva a estudios regionales precisar en cuántos pueblos, al perder sus bienes propios, descendió la escolarización, tanto de blancos como de indios, supone ont du être nombreuses. Cree probar esa tesis con un argumento risible, pero que él toma muy seriamente: maints documents de mediados del siglo XIX son preciosos índices de la amplitud de la alfabetización del Antiguo Régimen, destruida por las leyes liberales y sin ser reemplazada de inmediato. ${ }^{26}$

De esos muchos documentos sólo exhibe dos: en Matamoros, Puebla, el 28 de abril de 1856 , protestan porque se les quería enviar a Yucatán, cuando estaba en su apogeo la venta de mayas a Cuba; San Francisco Acautla, Estado de México, el 6 de marzo de 1868 , protestó contra la usurpación de sus tierras por la hacienda de Zoquiapan: "siguen las firmas de los habitantes del lugar"." Dos documentos no son "muchos", firmar no equivale a saber leer y escribir, y tendría que sacar el porcentaje de cincuenta del total de los habitantes de Matamoros. Por supuesto, olvida las estadísticas sobre el corto número de personas que en el campo hablaban el español, cifras de fácil consulta y que constan en algunas memorias de los estados. No menciona archivos porque parecen no gustarle; al menos en este libro sólo menciona el de Diego Abad de Santillán.

Cuando el autor no puede probar una afirmación pide estudios regionales sobre el tema en cuestión, pero no ofrece emprenderlos él. Tacha de inspiradas en "la lógica ideológica" las cifras de José Diaz Covarrubias favorables al liberalismo, y a Francisco Larroyo lo califica de "muy serio autor contemporáneo", porque, según éste, sólo había dos establecimientos destinados a la enseñanza elemental en la Nueva España. Una "lógica ideológica" de signo contrario campea en este calificativo, porque Larroyo en este punto no tiene autoridad. ${ }^{28}$

Caricaturiza al positivismo en México cuando escribe que Porfirio Díaz no fue positivista sino un "liberal histórico", como si hubiera sido necesario que Diaz hubiera estudiado a Comte y a Spencer para que hubiera apoyado el positivismo. Soslaya que Gabino Barreda fue el introductor del positivismo en la Escuela Preparatoria en 1868 , y que en su primera presidencia, Díaz no afectó lo básico del positivismo de esa escuela; asimismo, que en la presidencia de Manuel González, los jacobinos se batieron en retirada y comenzaron a tomar posiciones los positivistas. ${ }^{29}$

Rechaza que los positivistas hayan sido los ideólogos encargados de vestir de una manera honorable un caudillismo protector de los intereses extranjeros, y que fueron ellos quienes lucharon por hacer pasar el régimen porfirista de un poder puramente personal a una democracia, restringida, pero regida por la ley. Fueron civilistas, aceptaron a Díaz por necesidad, pero rechazaron a Bernardo Reyes. Además, Justo Sierra, en 1892 y Francisco Bulnes en 1893 (los más brillantes intelectuales positivistas), desmienten el

${ }^{26}$ Guerra, op. cit., t. I, p. 241-244.

27 Reina, Las rebeliones..., op. cit., p. 246-251, 72-74.

28 Guerra, op. cit., t. I, p. 366.

29 González Navarro, El porfiriato..., op. cit. 
reproche de que eran enemigos de la democracia, al afirmar que tal acusación "sólo obedece a motivos puramente ideológicos". 30 Nada importa que Sierra en La Libertad, haya definido desde 1878 la ideología del Porfiriato y que ambos, más Sierra que Bulnes, hayan sido políticos sumisos al servicio de ese régimen. Es cierto que los positivistas intentaron en 1892 y en 1903 sacudirse la tutela de Díaz; fracasaron pero no se rebelaron, ni siquiera se separaron de ese régimen, antes bien continuaron luchando en él. directa o indirectamente.

Cuando el autor llega al final del Porfíriato suma a sus dos héroes (Maximiliano y Porfirio Diaz) a Francisco I. Madero. En efecto, exculpa a éste de que haya dado un lugar principal a la libertad, como cuando dijo a los obreros en Orizaba que ellos no querian pan sino libertad pues con ésta conquistarían el pan. Esa frase se saca de contexto para atacarlo, porque resultaria incomprensible que en una zona trabajada por la propaganda radical del Partido Liberai Mexicano hubiera tenido tanto éxito. Al autor no le sorprende que cuando Madero fue presidente hayan ido de la mano la vida democrática más real que México ha tenido y el desarrollo del movimiento obrero. Tampoco le sorprende que hayan ido de la mano la represión del movimiento obrero y la democracia ficticia del presidente Venustiano Carranza. Tacha de doloso el ocultamiento del acercamiento de Madero a los católicos (es de suponerse que quiso decir el partido Católico). ${ }^{31}$

Supone que un estudio detallado de las sociedades mutualistas mostraría que "parece" que en su mayor parte tuvieron origen liberal, masónico o en algún club liberal de los años 1901-1903. ${ }^{32}$ Esa hipótesis deja fuera a las numerosas sociedades mutualistas fundadas desde mediados del siglo XIX, algunas con intervención eclesiástica o gubernamental. ${ }^{33}$

Cuando en 1910 una multiplicidad de revueltas se despliegan en el vacio del poder se pregunta patéticamente: "¿Es esto verdaderamente una revolución?". La mayoría de estas revueltas, aisladas, fracasan inicialmente. Sin embargo, triunfan en Chihuahua, estado que reunía todas las condiciones para una explosión revolucionaria: numerosas pequeñas minas, grandes empresas de extranjeros, ranchos y haciendas, falta de trabajo en algunos pueblos, larga tradición de oposición y de revueltas, fermento ideológico del magonismo extendido por una población muy móvil. Esta explicación de Chihuahua es correcta y tranquila. En cambio, el centro oeste y el Bajío, regiones de emigración, con menores tensiones sociales, menos afectadas por la crisis, con una práctica religiosa muy elevada (a contrario sensu, no era el caso del norte $y$, por tanto, fue excesiva la generalización de que la sociedad mexicana era profundamente católica), con simpatía por Madero pero con débiles centros de sociabilidad política moderna (logias, clubes liberales, magonismo) no son actores principales en la $\mathrm{Re}$ -

Guerra, op. cit., t. I, p. 342-343, 351-354, 389; t. II, p. 85.

${ }^{31}$ Ibid., t. II, p. 185-187.

32 Ibid., t. II, p. 206.

${ }^{33}$ González Navarro, El Porfiriato..., op. cit. p. 344-353; Moisés González Navarro, La pobreza en México, México, El Colegio de México, 1985, p. 124-125, 127. 130. 
volución, al igual que las tradicionalistas Oaxaca, Chiapas y Yucatán, por el fantasma de la guerra de castas. ${ }^{34}$ Esta afirmación de nueva cuenta es temeraria: la escasa y tardía participación de $\mathrm{Yu}$ catán en la Revolución también podría atribuirse al tradicionalismo y a los buenos precios del henequén.

Las conclusiones son decepcionantes, sobre todo si se comparan con los prólogos de Chevalier y del propio autor, para quien el Porfíriato es una ficción democrática, al menos como se entiende en Europa y en los Estados Unidos. Ninguna de las disposiciones de la constitución fue verdaderamente respetada. Hay un patente anticlericalismo pese a que los católicos practicantes constituian la gran mayoría de la población, y de nueva cuenta olvida la peculiaridad del centro oeste y del Bajio, zonas a las que sí se podría aplicar tal calificativo. El sufragio es ficticio, siempre lo habia sido; Porfirio Díaz designaba a los candidatos electos y la división de poderes no existía. Hasta aquí todo es obvio y banal.

Contrasta el alto porcentaje de analfabetos $(80 \%)$ con el alto nivel intelectual de la clase política $(84 \%)$ que hizo estudios superiores. Añade el compromiso con la Iglesia hasta el final, cosa comprobada, y con los pueblos hasta 1890 , lo que no prueba con el supuesto pacto "implícito". También se refiere a la archisabida disminución de la autonomía municipal. Es discutible su tesis de que la Revolución sólo fue posible por la acumulación excepcional de las crisis. 35

Se relaciona con esta última conclusión el comentario del autor a mis Estadísticas Sociales del Porfiriato, publicadas por la Dirección de Estadística, no por El Colegio de México como dice. Rechazo el donativo de la dirección de los dos tomos de las Estadisticas Económicas del Porfiriato que el autor me atribuye en las páginas 472 y 513 del tomo II de su libro, no porque me desagrade ese honor, sino porque Fernando Rosenzweig muy claramente dice en la página 23 de Fuerza de Trabajo y Actividad Económica que él es el responsable del grupo que las editó.

También el autor me acusa de haber confundido la clasificación de los hombres que habitan en el campo con el tipo de localidades en que viven. ${ }^{36}$ Para esto le habria bastado leer en la página 6 de las Estadisticas Sociales del Porfiriato que el destino final de éstas sería el tomo IV de la Historia Moderna de México, "cuya publicación se iniciará pronto, tomo cuya redacción me ha sido confiada". Trece meses después se publicó tal tomo. Don Daniel Cosío Villegas, en su Cuarta Llamada Particular confirma que el apoyo estadístico de ese tomo se publicó aparte bajo el título de Estadísticas Sociales del Porfiriato 1877-1910. Está claro que estas Estadisticas sólo pueden entenderse relacionándolas con el tomo IV de la Historia Moderna de México.

En la página 209 de ese tomo IV distingo propiedades comunales e individuales y advierto que es limitada la posibilidad de compararlas "por la vaguedad de la nomenclatura y la falta de datos exactos sobre la desamortización de las comunidades indígenas. Es decir, el concepto demográfico de localidades no es exacta-

${ }^{34}$ Guerra, op. cit., t. II, p. 212, 257, 265-266, 297.

${ }^{35}$ Ibid., t. II, p. $305-318$.

36 Ibid., t. II, p. 472. 
mente comparable al de propiedad agrícola, el primero es más restringido. Con esas reservas (subrayado de MGN) puede recordarse que el grupo de localidades de propiedad comunal en 1877 sumaba 6937 contra 20574 propiedades individuales (haciendas y ranchos)". En aquella ocasión me pregunté "¿Qué era un rancho y qué una hacienda?". Califiqué de plausible el esfuerzo de Mc Bride por precisar cuantitativamente esos conceptos pero lo rechacé, entre otras razones, porque no tomaba en cuenta que una sola persona podia ser dueña de varias propiedades y olvidaba ciertas pequeñas propiedades a que se refiere un informe hacendario de 1877 , en el que se incluyen al lado de ranchos y haciendas 10825 sitios o terrenos de labor y 6927 terrenos para horticultura. ${ }^{37}$ En 1958 publiqué un artículo en el que' reitero el rechazo de la identificación de rancho como localidad política y como tenencia de la tierra. ${ }^{38}$

Desde la primera edición de mi Confederación Nacional Campesina, (1968, p. 41) explícitamente señalo que el censo de 1910 al enumerar que el $88.4 \%$ de la población agrícola eran peones y sólo el $0.02 \%$ hacendados y el resto agricultores era impreciso, entre otras muchas razones, porque el número de haciendas supera en mucho al de hacendados y el rubro agricultores mezcla pequeños y medianos propietarios, arrendatarios, aparceros, comuneros y trabajadores libres. A contrario sensu, a quienes se censó como peones debiera considerarse acasillados, cosa también inexacta porque resultaria una cifra muy elevada. En un artículo de 1969 reitero que el concepto demográfico de localidad no es exactamente equiparable al agrario. Recuerdo que González Roa calculó que el $85 \%$ de los ranchos estaba comprendido en las haciendas. Para corroborar la imprecisión del término peón señalo que en Campeche en 1869 y en Yucatán en 1883-1885 se publicaron estadisticas especificas sobre los sirvientes endeudados. ${ }^{39}$

En suma, mis Estadisticas Sociales sólo se pueden entender en relación con mi libro El Porfiriato. La Vida Social, y en éste preciso las limitaciones de aquéllas. Es, por tanto, innecesaria toda su retórica contra mis Estadísticas. También sale sobrando su "confesión" de nuestra ignorancia actual "sobre la situación global del campo en México en vísperas de la Revolución. Mieux vaut, cependant, un aveu d'ignorance qu'une fausse certitude". 40

Si el Quijote de la estadística se hubiera tomado la molestia de leer El Porfiriato. La Vida Social (lo cita en la página 513) tal vez hubiera evitado varios errores. Pero esto es pedirle peras al olmo, pues ha declarado la guerra a libros inútiles. En cumplimiento de la primera de las obras de misericordia debo informarle que sí hay fuentes globales impresas en las que se pueda estudiar el monto de las tierras comunales en vísperas de la Revolución: los censos agrarios de 1930 a la fecha. $F$. Chevalier pudo conocer algunos de ellos porque constan en La Confederación Nacional Campesina

37 González Navarro, El Porfiriato..., op. cit., p. 210-212.

38 González Navarro, "Indio y propiedad en Oaxaca", en Historia Mexicana, vol. VIII, octubre-diciembre, 1958, núm. 2, p. 175-191.

${ }^{39}$ González Navarro, "Tenencia de la Tierra y Población Agrícola (1877-1960)", en Caravelle 12, Toulouse, Université de Toulouse, 1969, 116-121. González Navarro, Raza y Tierra, México, El Colegio de México, 1970, p. 198-200.

${ }^{40}$ Guerra, op. cit., t. II, p. 485. 
que escribí en París, en noviembre de 1966-abril 1967, invitado por él para escribir ese libro. En suma, con estas explicaciones se viene abajo el "artificioso edificio" 11 de Guerra.

En suma, este libro es doctoral (y no porque sea una tesis de doctorado), fantasioso, voluntarista, polémico e ingenuo. Esto último porque lo nuevo para el autor le parece nuevo para todos los demás. Por ejemplo, el concepto de la sociedad tradicional lo hemos utilizado varios, algunos siguiendo el tipo de denominación de Max Weber. Es plausible el uso de la larga duración, del Antiguo Régimen a la Revolución, acaso el mayor mérito de la obra. Esta tiene dos limitaciones principales: la apología del Antiguo Régimen y cierta denigración del liberalismo y de la Revolución, y la pobreza de las fuentes de fines de la Colonia hasta el inicio del Porfiriato, acaso explicable porque puso su mayor empeño en el corpus bibliográfico. El segundo gran mérito de este libro es ofrecer una visión global de la sociedad. De cualquier modo, pese al entusiasmo del caballeroso prologuista, no es un "gran libro" que dé otra dimensión a la historia de México; pudo ser un gran libro.

${ }^{41}$ Estas palabras que Jean Meyer dedica a mis Estadísticas Sociales del Porfiriato se aplican a las de Guerra. Véase Jean Meyer, "Haciendas y Ranchos, Peones y Campesinos en el Porfiriato, algunas falacias estadisticas", en Historia Mexicana, vol. XXXV enero-marzo, 1986 núm. 3, p. 493. 